\title{
ANALISIS KEPUASAN DAN LOYALITAS PELANGGAN PROVIDER DENGAN PENDEKATAN STRUCTURAL EQUATION MODELLING
}

\author{
Nurul Aziza' ${ }^{1}$, Slamet Hariyono ${ }^{2}$ \\ Teknik Industri, Fakultas Teknik \\ Universitas Maarif Hasyim Latif, Sidoarjo, Indonesia \\ e-mail: ${ }^{1}$ nurul_aziza@dosen.umaha.ac.id, ${ }^{2}$ slamet.hary@gmail.com
}

Diterima: 18 Nopember 2017. Disetujui : 15 Desember 2017. Dipublikasikan : 18 Desember 2017

(C)2017 -TESJ Fakultas Teknik Universitas Maarif Hasyim Latif. Ini adalah artikel dengan

akses terbuka di bawah lisensi CC BY 4.0 (https://creativecommons.org/licenses/by/4.0/)

\begin{abstract}
ABSTRAK
Sekarang ini, internet memberikan dampak besar terhadap perkembangan media komunikasi diberbagai belahan dunia. Begitu cepat dan mudahnya komunikasi dapat berjalan dengan efisien. Jaringan untuk melakukan komunikasi melalui smartphone, menjadikan mobilitas komunikasi menjadi lebih mudah dan lancar untuk urusan bisnis. Untuk itulah penelitian ini dilakukan yang bertujuan mengetahui kepuasan dan loyalitas konsumen pengguna layanan jaringan provider. Penelitian ini merupakan explanary research yang bertujuan mendeskripsikan hubungan antara variabel-variabel dengan uji hipotesis. Metode pengambilan sampel menggunakan probability sampling dengan ukuran sampel lima kali lipat dari jumlah indikator yang sudah ditentukan yaitu sebanyak 14 indikator, sehingga total jumlah responden sebanyak 60 pelanggan. Metode analisis yang digunakan yaitu metode SEM (Strucutral Equation Modelling). Berdasarkan pengolahan data, menunjukkan terdapat pengaruh positif dan signifikan kualitas produk, kualitas layanan, terhadap kepuasan dan loyalitas pelanggan dengan nilai $\mathrm{R}^{2} \quad 0,546$ atau sebesar $54 \%$ memberikan kontribusi pengaruh. Sedangkan impact terhadap manajerial dari penelitian ini yaitu pihak manajemen untuk dapat meningkatkan dan memfokuskan pada pada performansi produk, kualitas layanan yang berdampak kepada kepuasan pelanggan yang pada akhirnya dapat berdampak pada tingkat loyalitas konsumen.
\end{abstract}

Kata kunci: kepuasan, layanan, performansi, structural equation modelling, sem

\section{PENDAHULUAN}

Hal yang sangat penting untuk membantu manusia adalah komunikasi. Komunikasi menjadi semakin mudah saat ini dengan adanya mobile phone. Mobile phone yang berbasis CDMA ataupun GSM semakin memudahkan manusia melakukan komunikasi dengan manusia lainnya. Saat ini provider menyediakan 2G, 3G, dan 4G LTE. Pelayanan yang reliable dan always on istilahnya, telah diberikan kepada konsumen yang bertujuan sebagai pengendalian kualitas layanan. Kinerja perangkat jaringan berpengaruh terhadap kualitas layanan selama pengoperasian yaitu antara lain ketersediaan power. Perangkat jaringan ini sering mengalami gangguan yang berpotensi menyebabkan pada gangguan kualitas service pada provider. Oleh sebab itu perlu dilakukan maintenance secara berkala untuk menjaga agar pelanggan selalu menggunakan produk provider.

Prinsip performansi produk adalah keterkaitan antara kepuasan konsumen sebagai penggina melalui kualitas produk itu sendiri dan kualitas layanan. Apabila seseorang yang telah membeli, kemudian melakukan transaksi pembelian kembali dan dengan sukarela memberitahu orang lain untuk membeli dengan berbagi pengalaman baiknya tentang produk tersebut
(Wardono, Hibino, \& Koyama, 2012). Maka bisa dikatakan konsumen tersbut memiliki loyalitas terhadap produk. Berdasarkan (Dutka, 1995) menyatakan bahawa ukuran kepuasan pelanggan berdasar atribut pembentuk kepuasan yaitu yang berhubungan dengan produk, layanan dan pembelian. Sedangkan ukuran loyalitas menurut (Bowen \& Chen McCain, 2015) mengatakan bahwa konsumen yang loyal akan membantu mempromosikan produk perusahaan.

Menurut (Kotler, 2004), bahwa kepuasan adalah perasaan senang atau kekecewaan seseorang terhadap hasil dengan membandingkan antara performansi produk yang diterima dengan ekspektasi yang diharapkan. Penelitian ini didasarkan pada penelitian (Hidayat, 2009) tentang pengaruh kualitas layanan dan kualitas produk terhadap tingkat kepuasan dan loyalitas pada nasabah Bank Mandiri Jatim. Penelitian lain yang mendukung yaitu penelitian ini adalah tentang pengaruh kualitas produk terhadap kepuasan dan loyalitas pelanggan telkom flexi (Wedarini, 2012).

\section{METODE PENELITIAN}

Lokasi penelitian ini adalah wilayah Sidoarjo dan Surabaya berdasarkan (Hadi, 2000) yang menyatakan 
bahwa populasi adalah wilayah generalisasi yang terdiri dari obyek/subyek yang memiliki kualitas dan karakteristik tertentu. Penelitian ini menggunakan metode PLS-SEM adalah pilihan terbaik jika jumlah sampel kecil, namun tetap harus memenuhi persyaratan minimum jumlah sampel (Hair Jr, Hult, Ringle, \& Sarstedt, 2016).

\section{Teknik Pengumpulan Data}

Pengumpulan data dengan melalui penyebaran angket atau kuesioner yang memuat tentang daftar pertanyaan untuk memperoleh data dan keterangan dari responden. Skala pengukuran menggunakan skala Likert 5 poin.

\section{Identifikasi Variabel}

Variabel dalam penelitian ini yaitu performansi produk $\left(X_{1}\right)$, kualitas layanan $\left(X_{2}\right)$, kepuasan pelanggan $\left(Y_{1}\right)$, dan loyalitas pelanggan $\left(Y_{2}\right)$.

Uji hipotesis penelitian adalah:

1. Pengaruh performansi produk $\left(X_{1}\right)$ terhadap kepuasan pelanggan $\left(Y_{1}\right)$

2. Pengaruh kualitas layanan $\left(X_{2}\right)$ terhadap kepuasan pelanggan $\left(Y_{1}\right)$

3. Pengaruh performansi produk $\left(X_{1}\right)$ terhadap loyalitas pelanggan $\left(Y_{2}\right)$

4. Pengaruh kualitas layanan $\left(X_{2}\right)$ terhadap loyalitas pelanggan $\left(Y_{2}\right)$

5. Pengaruh kepuasan pelanggan $\left(Y_{1}\right)$ terhadap loyalitas pelanggan $\left(Y_{2}\right)$

Selanjutnya dilakukan pengolahan data dengan menggunakan software smartPLS 3.0. Pengujian validitas menggunakan uji convergent validity dan discrimant validity. Dengan software smartPLS 3.0 hasil uji validitas dapat dilihat pada hasil loading factor untuk setiap indikator kontruk dengan nilai loading factor > 0,7. Nilai AVE (average variance extracted) dapat juga dijadikan ukuran validitas yang bernilai >0,5. Discriminant validity dapat dilihat pada nilai cross loading untuk setiap variabel harus $>0,7$.

Pengujian reliability dilakukan dengan Cronbach Alpha dan Composite Reliability. Untuk pengujian reliabilitas konstruk menggunakan Composite Reliability dimana nilainya harus $>0,7$ untuk penelitian yang bersifat confirmatory dan nilai rentang 0,6 - 0,7 untuk penelitian yang sifatnya explanary.

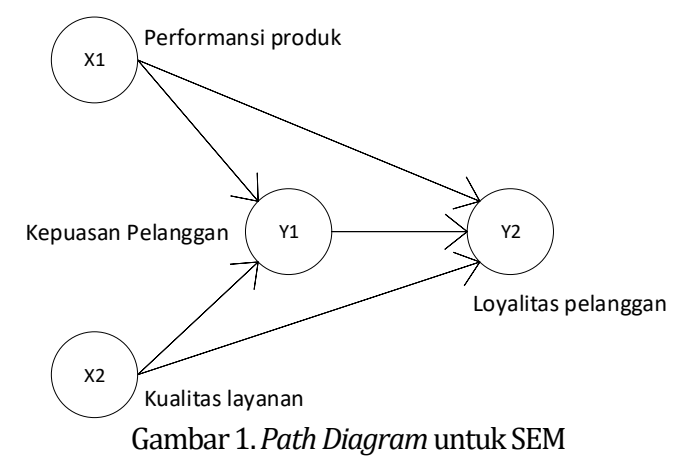

Path diagram untuk penelitian ini dapat dilihat pada gambar 1 . Penjelasan path diagram dapat dilihat pada tabel 1 .

\begin{tabular}{c|l}
\multicolumn{2}{c}{ Tabel 1. Variabel laten } \\
\hline & \multicolumn{1}{c}{ Variabel } \\
\hline Variabel laten Eksogen & Performansi produk $\left(X_{1}\right)$ \\
\cline { 2 - 2 } & Kualitas layanan $\left(X_{2}\right)$ \\
\hline Variabel laten endogen & Kepuasan pelanggan $\left(Y_{1}\right)$ \\
\cline { 2 - 2 } & Loyalitas pelanggan $\left(Y_{2}\right)$ \\
\hline
\end{tabular}

Persamaan struktural untuk model yang akan diuji adalah sebagai berikut:

$Y_{1}=\gamma_{1} X_{1}+\gamma_{2} X_{2}+\zeta_{1}$

$Y_{2}=\gamma_{3} X_{1}+\gamma_{4} X_{2}+\beta_{1} Y_{1}+\zeta_{2}$

Keterangan:

$\gamma$ (gama): koefisien pengaruh variabel eksogen terhadap variabel endogen

$\beta$ (beta) : koefisien pengaruh variabel endogen terhadap variabel endogen

$\varsigma$ (Zeta) : Galat model

Persamaan measurement model sebagai berikut:

1. Untuk performansi produk $\left(\mathrm{X}_{1}\right)$

$$
\begin{aligned}
& X_{1.1}=\lambda_{1} X_{1}+\delta_{1} \\
& X_{1.2}=\lambda_{2} X_{1}+\delta_{2} \\
& X_{1.3}=\lambda_{3} X_{1}+\delta_{3}
\end{aligned}
$$

2. Untuk kualitas layanan $\left(\mathrm{X}_{2}\right)$

$$
\begin{aligned}
& X_{2.1}=\lambda_{4} X_{2}+\delta_{4} \\
& X_{2.2}=\lambda_{5} X_{2}+\delta_{5} \\
& X_{2.3}=\lambda_{6} X_{2}+\delta_{6}
\end{aligned}
$$

Tabel 2. Variabel dalam model

\begin{tabular}{ccl}
\hline \multicolumn{3}{c}{ Variabel Indikator } \\
\hline$X_{1}$ & $X_{1.1}$ & Jaringan provider tanpa hambatan \\
& $X_{1.2}$ & Produk provider memiliki tampilan yang mudah dimengerti \\
& $X_{1.3}$ & Produk provider memiliki kelengkapan penggunaan \\
\hline$X_{2}$ & $X_{2.1}$ & Tanggapan terhadap permintaan ataupun keluhan pelanggan \\
& $X_{2.2}$ & Jaminan jika produk bermasalah akan datang kembali \\
& $X_{2.3}$ & Pelayanan sepenuh hati \\
\hline$Y_{1}$ & $Y_{1.1}$ & Manfaat sesuai dengan harapan pelanggan terhadap produk \\
& $Y_{1.2}$ & Jaminan atas kualitas layanan yang diberikan \\
& $Y_{1.3}$ & Harapan akan hubungan yang selalu baik \\
\hline$Y_{2}$ & $Y_{2.1}$ & Merekomendasikan produk kepada teman \\
& $Y_{2.2}$ & Mengajak orang lain untuk menggunakan produk \\
& $Y_{2.3}$ & Memiliki keinginan untuk berpindah ke produk lain yang sejenis \\
\hline
\end{tabular}


3. Untuk kepuasan pelanggan $\left(\mathrm{Y}_{1}\right)$

$$
\begin{aligned}
& Y_{1.1}=\lambda_{7} Y_{1}+\epsilon_{1} \\
& Y_{1.2}=\lambda_{8} Y_{1}+\epsilon_{2} \\
& Y_{1.3}=\lambda_{9} Y_{1}+\epsilon_{3}
\end{aligned}
$$

4. Untuk loyalitas pelanggan $\left(\mathrm{Y}_{2}\right)$

$$
\begin{aligned}
& Y_{2.1}=\lambda_{10} Y_{2}+\epsilon_{4} \\
& Y_{2.2}=\lambda_{11} Y_{2}+\epsilon_{5} \\
& Y_{2.3}=\lambda_{12} Y_{2}+\epsilon_{6}
\end{aligned}
$$

Keterangan:

$\lambda$ (lambda) : loading factor

$\delta$ (delta) : galat pengukuran variabel manifest untuk variabel eksogen

$\varepsilon$ (epsilon): galat pengukuran variabel manifest untuk variabel endogen

Untuk keterangan variabel dapat dilihat pada tabel 2.

\section{HASIL DAN PEMBAHASAN}

Hasil uji SEM dari path diagram model dengan smartPLS dapat dilihat pada gambar 2 .

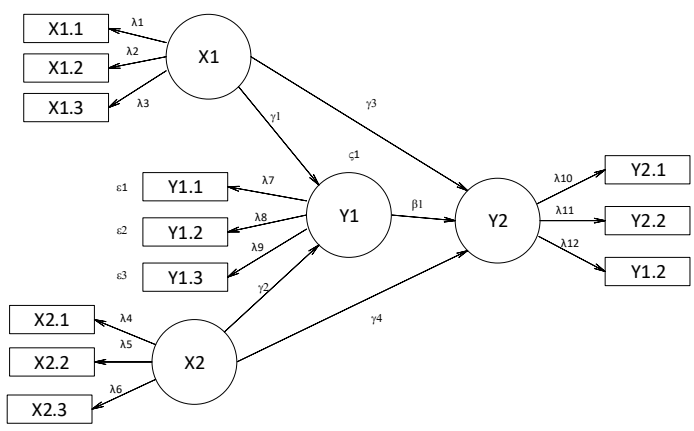

Gambar 2. Path diagram model dengan smartPLS

Langkah selanjutnya melakukan pengolahan data dengan data dari 60 responden dapat dilihat pada gambar 3 .

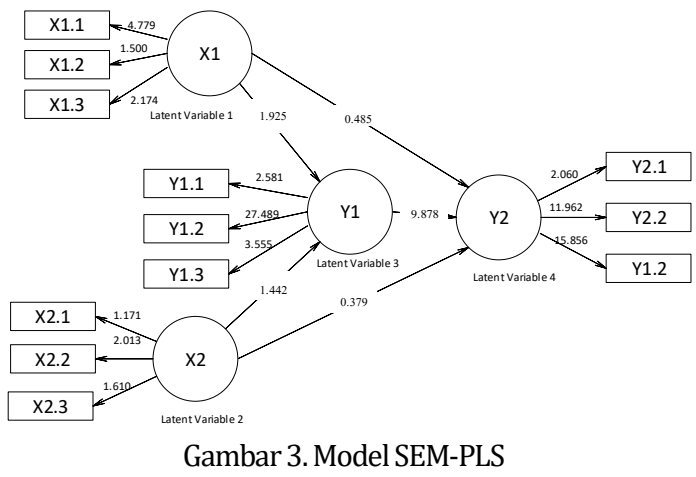

Sedangkan hasil uji validitas instrumen dapat dilihat pada tabel 3.

Berdasarkan tabel 3, menunjukkan bahwa nilai korelasi antara item pertanyaan dengan total item terletak antara 0,393 dan 0,713 . Terlihat pula bahwa nilai signifikansi korelasi (Sign. R) lebih kecil dari 0,05, nilai r tabel dengan $\mathrm{N}=60$ pada $\alpha=0,05$ sehingga ditemukan nilai $r$ tabel sebesar 0,254. Dengan demikian kesimpulannya bahwa nilai $r$ hitung $>r$ tabel $=0,254$, sehingga seluruh item dalam variabel yang diteliti dinyatakan valid.

Tabel 3. Hasil uji validitas instrumen dengan SPSS

\begin{tabular}{ccccc}
\hline Variabel & Indikator & $\mathrm{R}$ & Sign.r & keterangan \\
\hline$X_{1}$ & $X_{1.1}$ & 0,484 & 0,254 & valid \\
& $X_{1.2}$ & 0,422 & 0,254 & valid \\
& $X_{1.3}$ & 0,427 & 0,254 & valid \\
\hline$X_{2}$ & $X_{2.1}$ & 0,395 & 0,254 & valid \\
& $X_{2.2}$ & 0,396 & 0,254 & valid \\
& $X_{2.3}$ & 0,412 & 0,254 & valid \\
\hline$Y_{1}$ & $Y_{1.1}$ & 0,392 & 0,254 & valid \\
& $Y_{1.2}$ & 0,713 & 0,254 & valid \\
& $Y_{1.3}$ & 0,435 & 0,254 & valid \\
\hline$Y_{2}$ & $Y_{2.1}$ & 0,378 & 0,254 & valid \\
& $Y_{2.2}$ & 0,629 & 0,254 & valid \\
& $Y_{2.3}$ & 0,610 & 0,254 & valid \\
\hline
\end{tabular}

Uji reliabel instrumen dapat dilihat pada tabel 4.

Tabel 4. Hasil uji reliabilitas instrumen Variabel Alpha keterangan

\begin{tabular}{ccc}
\hline$X_{1}$ & 0,656 & reliabel \\
\hdashline$X_{2}$ & 0,672 & reliabel \\
\hline$Y_{1}$ & 0,641 & reliabel \\
$Y_{2}$ & 0,637 & reliabel \\
\hline
\end{tabular}

Tabel 5. Reliability statistic

\begin{tabular}{c|c}
\hline Cronbach's Alpha & N of items \\
\hline .0672 & 12
\end{tabular}

Berdasarkan tabel 4 dan tabel 5, diketahui nilai alpha sebesar 0,672, kemudian nilai ini dibandingkan dengan nilai $r$ tabel dengan $\mathrm{N}=60-2$, dalam distribusi nilai $r$ tabel signifikansi 5\% diperoleh nilai $r$ tabel sebesar 0,254. Maka kesimpulannya bahwa nilai aplha $=0,672>$ nilai $r$ tabel $=0,254$ sehingga seluruh item dalam variabel yang diteliti dinyatakan reliabel dan dapat digunakan dalam analisis selanjutnya.

\section{Interpretasi hasil uji SmartPLS}

Hasil olah data dengan smartPLS didapatkan sebagai berikut:

\section{Cross loading}

Cross loading bertujuan untuk menilai apakah konstruk memiliki discriminant validity yang memadai dengan cara membandingkan hubungan antar indikator variabel dengan korelasi indikator tersebut dengan variabel lainnya. Apabila indikator konstruk memiliki nilai lebih tinggi dibandingkan dengan hubungan indikator tersebut terhadap variabel yang lain, maka konstruk memiliki nilai discriminant validity yang tinggi pula. Dengan kata lain bisa dikatakan bahwa indikator variabel lebih baik dibandingkan dengan indikator variabel lainnya.

Berdasarkan tabel 6 terlihat bahwa variabel endogen loyalitas pelanggan $\left(Y_{2}\right)$ memiliki prediksi indikator yang baik dibandingkan dengan indikator blok lainnya. Variabel 
kepuasan pelanggan $\left(Y_{1}\right)$ pada indikator $Y_{1.2}$ memiliki nilai paling tinggi yaitu 0,927 .

\begin{tabular}{|c|c|c|c|c|}
\hline \multicolumn{5}{|c|}{ Outer loadings } \\
\hline Indikator & $X_{1}$ & $X_{2}$ & $Y_{1}$ & $Y_{2}$ \\
\hline$X_{1.1}$ & 0,868 & & & \\
\hline$X_{12}$ & 0,466 & & & \\
\hline$X_{13}$ & 0,621 & & & \\
\hline$X_{21}$ & & 0,422 & & \\
\hline$X_{22}$ & & 0,752 & & \\
\hline$X_{23}$ & & 0,637 & & \\
\hline$Y_{1.1}$ & & & 0,501 & \\
\hline$Y_{12}$ & & & 0,927 & \\
\hline$Y_{13}$ & & & 0,583 & \\
\hline$Y_{21}$ & & & & 0,390 \\
\hline$Y_{22}$ & & & & 0,832 \\
\hline$Y_{23}$ & & & & 0,870 \\
\hline
\end{tabular}

\section{Discriminant Validity}

Tujuan discriminant validity pada indikator refleksif dapat dilihat pada crossloading. Cara lain untuk menilai discriminant validity dapat dilakukan dengan cara membandingkan square of average variance extracted (AVE) untuk setiap variabel dengan nilai korelasi antara variabel. Model akan memiliki discriminant validity jika akar dari AVE untuk setiap variabel lebih besar dari korelasi antara konstruk (Ghozali, 2008). Jika nilai akar AVE lebih tinggi daripada korelasi antar variabel yang lain, maka dikatakan hasil ini menunjukkan bahwa discriminant validity yang tinggi.

Hasil discriminant validity ditunjukkan pada tabel 7.

Tabel 7. Hasil AVE

\begin{tabular}{ccccc}
\hline \multicolumn{5}{c}{ Average Variance Extracted } \\
\hline Variabel & $\begin{array}{c}\text { Original } \\
\text { sample }\end{array}$ & $\begin{array}{c}\text { Sample } \\
\text { mean }\end{array}$ & $\begin{array}{c}\text { Standart } \\
\text { deviation }\end{array}$ & T.statistic \\
\hline$X_{1}$ & 0,452 & 0,433 & 0,061 & 7,384 \\
\hline$X_{2}$ & 0,383 & 0,375 & 0,052 & 7,320 \\
\hline$Y_{1}$ & 0,483 & 0,487 & 0,058 & 8,313 \\
\hline$Y_{2}$ & 0,534 & 0,539 & 0,051 & 10,420 \\
\hline
\end{tabular}

Berdasarkan tabel 7 dengan nilai $\lambda$ pada masingmasing indikator $>0,5$ dan nilai AVE (original sample) pada variabel loyalitas pelanggan dengan nilai 0,534>0,5. Maka dapat disimpulkan bahwa model yang dibuat sudah benar dan variabel laten dan indikatornya signifikan saling berpengaruh.

\section{Composite Reliability}

Pengujian discriminant validity juga dapat ditunjukkan dengan nilai Composite Reliabilitynya. Yaitu dengan mengukur nilai antar variabel apakah mempunyai reliabilitas yang baik atau tidak apabila variabel penelitian memiliki nilai diatas 0,70 (Nunnally \& Bernstein, 1967). Berikut ini hasil pengolahan data PLS untuk Composite Reliability.

Berdasarkan tabel 8 bahwa nilai composite reliability variabel $>0,7$. Maka dapat disimpulkan nilai variabel laten kepuasan pelanggan sebesar 0,723 dan loyalitas pelanggan sebesar 0,758 maka dapat dikatakan bahwa nilai kehandalan baik sebagai konstruk yang diukur dengan indikatornya.

Tabel 8. Hasil olah data PLS Composite Reliability

\begin{tabular}{ccccc}
\hline \multicolumn{5}{c}{ Composite reliability } \\
\hline Variabel & $\begin{array}{c}\text { Original } \\
\text { sample }\end{array}$ & $\begin{array}{c}\text { Sample } \\
\text { mean }\end{array}$ & $\begin{array}{c}\text { Standart } \\
\text { deviation }\end{array}$ & T.statistic \\
\hline$X_{1}$ & 0,699 & 0,629 & 0,142 & 4,936 \\
\hline$X_{2}$ & 0,639 & 0,503 & 0,178 & 3,593 \\
\hline$Y_{1}$ & 0,723 & 0,710 & 0,073 & 9,858 \\
\hline$Y_{2}$ & 0,758 & 0,751 & 0,056 & 13,639 \\
\hline
\end{tabular}

\section{Hasil Uji Inner Model (Model Struktural)}

Pengujian inner model atau model strukturalyang dilakukan untuk melihat hubungan antara variabel, nilai signifikansi dan $R$-square dari model penelitian. Setelah mengetahui hubungan yang signifikan antara variabelnya, maka dapat disimpulkan hipotesisnya. Pengujian hipotesis dilakukan dengan metode resampling bootstrap. Statistik uji yang dipakai adalah uji statistik uji $\mathrm{T}$ dengan nilai t-statistik $>\mathrm{t}$ tabel $(\mathrm{df}=\mathrm{n}-2)$.

Hasil uji hipotesis dengan menggunakan nilai signifikansi 0,05 atau 5\%, diperoleh hipotesis statistiknya pada tabel 9 .

Tabel 9. Hasil R square

\begin{tabular}{ccccc}
\hline \multicolumn{5}{c}{ Tabel 9. Hasil R square } \\
\hline \multirow{2}{*}{ R-square } & & \\
\hline \multirow{2}{*}{ Original } & Sample & Standart & T.statistic \\
& sample & mean & deviation \\
\hline$Y_{1}$ & 0,0118 & 0,204 & 0,081 & 1,465 \\
$Y_{2}$ & 0,546 & 0,608 & 0,076 & 13,639 \\
\hline
\end{tabular}

Dari tabel 9 dapat disimpulkan bahwa nilai R-square seebsar 0,546 yang menujukkan bahwa variabel $X_{1}, X_{2}$, dan $Y_{1}$ memberikan kontribusi sebesar 54\% yang artinya memiliki hubungan yang signifikan antara variabel kepuasan dengan loyalitas pelanggan.

\section{Hasil uji hipotesis}

Statistik uji yang digunakan adalah uji $\mathrm{T}$ dengan nilai signifikansi $\alpha=0,05$ atau $5 \%$, dengan hasil pada tabel 10 .

Tabel 10. Result for outer weight

\begin{tabular}{cccccc}
\hline \multicolumn{5}{c}{ Outer weight } \\
\hline Variabel & $\begin{array}{c}\text { Original } \\
\text { sample }\end{array}$ & $\begin{array}{c}\text { Sample } \\
\text { mean }\end{array}$ & $\begin{array}{c}\text { Standart } \\
\text { deviation }\end{array}$ & T.statistic & Keterangan \\
\hline$X_{1,1}=X_{1}$ & 0,719 & 0,650 & 0,203 & 3,544 & $\mathrm{H}_{0}$ diterima \\
\hline$X_{12}=>X_{1}$ & 0,234 & 0,189 & 0,307 & 0,762 & $\mathrm{H}_{0}$ ditolak \\
\hline$X_{1,3}=>X_{1}$ & 0,430 & 0,393 & 0,266 & 1,615 & $\mathrm{H}_{0}$ ditolak \\
\hline$X_{21}=>X_{2}$ & 0,394 & 0,335 & 0,326 & 1,210 & $\mathrm{H}_{0}$ ditolak \\
\hline$X_{22}=>X_{2}$ & 0,694 & 0,534 & 0,372 & 1,866 & $\mathrm{H}_{0}$ ditolak \\
\hline$X_{23}=>X_{2}$ & 0,490 & 0,357 & 0,406 & 1,209 & $\mathrm{H}_{0}$ ditolak \\
\hline$Y_{1,1}=>Y_{1}$ & 0,196 & 0,197 & 0,130 & 1,508 & $\mathrm{H}_{0}$ ditolak \\
\hline$Y_{1,2}=>Y_{1}$ & 0,757 & 0,730 & 0,088 & 8,627 & $\mathrm{H}_{0}$ diterima \\
\hline$Y_{1,3}=>Y_{1}$ & 0,344 & 0,343 & 0,112 & 3,059 & $\mathrm{H}_{0}$ diterima \\
\hline$Y_{2,1}=>Y_{2}$ & 0,180 & 0,169 & 0,106 & 1,694 & $\mathrm{H}_{0}$ ditolak \\
\hline$Y_{22}=>Y_{2}$ & 0,472 & 0,478 & 0,063 & 7,494 & $\mathrm{H}_{0}$ diterima \\
\hline$Y_{23}=>Y_{2}$ & 0,617 & 0,598 & 0,079 & 7,782 & $\mathrm{H}_{0}$ diterima \\
\hline & & & & & \\
\hline
\end{tabular}

Didapatkan beberapa kesimpulan, yang didapatkan dengan membandingkan antara nilai t- 
statistik dengan nilai t-tabel dimana $\mathrm{df}=\mathrm{n}-2=2,00$ dengan ketentuan:

1. T-statistik > t-tabel ; berarti $\mathrm{H}_{\mathrm{o}}$ diterima dan ada pengaruh antara variabel dan indikatornya.

2. t-statistik < t-tabel ; berarti $\mathrm{H}_{\mathrm{o}}$ ditolak dan tidak ada pengaruh antara variabel dan indikatornya.

Dari analisis data di atas, maka dapat diberikan kesimpulan sebagai berikut:

1. Untuk pengujian outer model diperoleh tstatistik $=5,46$ dan t-tabel $\mathrm{df}=\mathrm{n}-2=2,00$. Karena nilai t-statistik > t-tabel, maka $\mathrm{H}_{0}$ diterima yang berarti indikator variabel bersifat valid

2. Untuk pengujian iiner model diperoleh tstatistik $=0,462$ dan $\mathrm{t}$-tabel $\mathrm{df}=\mathrm{n}-2=2,00$. Karena nilai t-statistik < t-tabel, maka $\mathrm{H}_{0}$ ditolak yang berarti indikator-indikator variabel laten bersifat valid. Ada hubungan kepuasan pelanggan terhadap loyalitas pelanggan.

3. Untuk pengujian hipotesis $\mathrm{X}_{1.1}$, dimana $\mathrm{t}$ statistik $>$ t-tabel $\{3,554>2,00\}$ sehingga $\mathrm{H}_{0}$ diterima yang berarti bahwa performansi produk dipengaruhi oleh jaringan provider tanpa hambatan.

4. Untuk pengujian hipotesis $\mathrm{X}_{1.2}$, dimana $\mathrm{t}$ statistik $>$ t-tabel $\{0,762<2,00\}$ sehingga $\mathrm{H}_{0}$ ditolak yang berarti bahwa performansi produk tidak dipengaruhi oleh produk provider memiliki tampilan yang mudah dimengerti.

5. Untuk pengujian hipotesis $\mathrm{X}_{1.3}$, dimana $\mathrm{t}$ statistik $<$ t-tabel $\{1,615<2,00\}$ sehingga $\mathrm{H}_{0}$ ditolak yang berarti bahwa performansi produk tidak dipengaruhi oleh produk provider yang memiliki kelengkapan dalam penggunaannya.

6. Untuk pengujian hipotesis $\mathrm{X}_{2.1}$, dimana tstatistik $<$ t-tabel $\{1,21<2,00\}$ sehingga $\mathrm{H}_{0}$ ditolak yang berarti bahwa menanggapi keluhan konsumen tidak berpengaruh terhadap kualitas layanan.

7. Untuk pengujian hipotesis $\mathrm{X}_{2.2}$, dimana tstatistik $<$ t-tabel $\{1,866<2,00\}$ sehingga $\mathrm{H}_{0}$ ditolak yang berarti bahwa jaminan jika produk bermasalah tidak berpengaruh terhadap kualitas layanan.

8. Untuk pengujian hipotesis $\mathrm{X}_{2.3}$, dimana $\mathrm{t}$ statistik $<$ t-tabel $\{1,209<2,00\}$ sehingga $\mathrm{H}_{0}$ ditolak yang berarti bahwa pelayanan sepenuh hati tidak berpengaruh terhadap kualitas layanan.

9. Untuk pengujian hipotesis $\mathrm{Y}_{1.1}$, dimana $\mathrm{t}$ statistik $<$ t-tabel $\{1,508<2,00\}$ sehingga $\mathrm{H}_{0}$ ditolak yang berarti bahwa mendapatkan manfaat yang sesuai dengan kebutuhan tidak berpengaruh terhadap kepuasan pelanggan.

10. Untuk pengujian hipotesis $\mathrm{Y}_{1.2}$, dimana $\mathrm{t}$ statistik > t-tabel $\{8,627>2,00\}$ sehingga $\mathrm{H}_{0}$ diterima yang berarti bahwa memberikan jaminan atas kualitas layanan berpengaruh terhadap kepuasan pelanggan.
11. Untuk pengujian hipotesis $\mathrm{Y}_{1.3}$, dimana tstatistik $>$ t-tabel $\{3,059>2,00\}$ sehingga $\mathrm{H}_{0}$ diterima yang berarti bahwa memberikan hubungan yang baik berpengaruh terhadap kepuasan pelanggan.

12. Untuk pengujian hipotesis $\mathrm{Y}_{2.1}$, dimana $\mathrm{t}$ statistik $<$ t-tabel $\{1,694<2,00\}$ sehingga $\mathrm{H}_{0}$ ditolak yang berarti bahwa rekomendasi produk kepada teman tidak berpengaruh terhadap loyalitas pelanggan.

13. Untuk pengujian hipotesis $\mathrm{Y}_{2.2}$, dimana $\mathrm{t}$ statistik $>$ t-tabel $\{7,494>2,00\}$ sehingga $\mathrm{H}_{0}$ diterima yang berarti bahwa mengajak orang lain untuk menggunakan produk berpengaruh terhadap loyalitas pelanggan.

14. Untuk pengujian hipotesis $\mathrm{Y}_{2.3}$, dimana $\mathrm{t}$ statistik $>$ t-tabel $\{7,782>2,00\}$ sehingga $\mathrm{H}_{0}$ diterima yang berarti bahwa tidak memiliki keinginan untuk berpindah produk yang sejenis berpengaruh terhadap loyalitas pelanggan.

Berdasarkan penelitian di atas, mengindikasikan bahwa terdapat variabel kepuasan pelanggan terhadap loyalitas pelanggan. Maka metode PLSSEM dapat digunakan untuk menganalisis hubungan antara variabel yang terdiri dari indikator-indikator yang mempengaruhinya. Metode ini juga mampu memberikan informasi mengenai lintas model pengukuran, model struktural serta tingkat hubungan antara variabelvariabel dan indikator sehingga pengolahan data dengan statistik PLS menajdi lebih mudah dan efisien.

\section{PENUTUP}

Berdasarkan hasil dan pembahasan dari penelitian ini didapatkan bahwa performasni produk dan kualitas layanan berpengaruh signifikan terhadap kepuasan pelanggan yang akan berdampak pada loyalitas pelanggan. Provider terus dituntut untuk meningkatkan kualitas layanan dan performansi produk agar dapat bersaing dengan provider lain. Untuk penelitian dimasa mendatang, penambahan variabel independen akan sangat membantu dalam mengidentifikasi faktor-faktor yang berpengaruh terhadap kepuasan pelanggan dan berdampak pada loyalitas pelanggan.

\section{UCAPAN TERIMA KASIH}

Terima kasih diucapkan kepada para responden yang khusus memberikan waktunya pada saat pengambilan data. Juga terucap kepada artikel sebelumnya yang dijadikan rujukan penelitian ini sehingga mampu mengembangkan penelitian lebih lanjut. 


\section{DAFTAR PUSTAKA}

Bowen, J. T., \& Chen McCain, S.-L. (2015). Transitioning loyalty programs: a commentary on "the relationship between customer loyalty and customer satisfaction." International Journal of Contemporary Hospitality Management, 27(3), 415-430.

Dutka, A. F. (1995). AMA handbook for customer satisfaction. NTC Business books.

Ghozali, I. (2008). Structural equation modeling: Metode alternatif dengan partial least square (pls). Badan Penerbit Universitas Diponegoro.

Hadi, S. (2000). Metodologi penelitian. Yogyakarta: Andi Yogyakarta.

Hair Jr, J. F., Hult, G. T. M., Ringle, C., \& Sarstedt, M. (2016). A primer on partial least squares structural equation modeling (PLS-SEM). Sage Publications.
Hidayat, R. (2009). Pengaruh kualitas layanan, kualitas produk dan nilai nasabah terhadap kepuasan dan loyalitas nasabah Bank Mandiri. Jurnal Manajemen Dan Kewirausahaan, 11(1), 59-72.

Kotler, P. (2004). Ten deadly marketing sins: signs and solutions. John Wiley \& Sons.

Nunnally, J. C., \& Bernstein, I. H. (1967). Psychometric theory (Vol. 226). McGraw-Hill New York.

Wardono, P., Hibino, H., \& Koyama, S. (2012). Effects of interior colors, lighting and decors on perceived sociability, emotion and behavior related to social dining. ProcediaSocial and Behavioral Sciences, 38, 362-372.

Wedarini, N. M. S. (2012). Pengaruh kualitas produk terhadap kepuasan dan loyalitas pelanggan telkom flexi. Jurnal Administrasi Bisnis, 7(1), 495-512. 